\title{
INFLUENCE OF WHITE SPACE ON TEXT SCANNING
}

\author{
Kata Jovančić (iD, Neda Milić Keresteš (D), Uroš Nedeljković (iD) \\ University of Novi Sad, Faculty of Technical Sciences, \\ Department of Graphic Engineering and Design, Novi Sad, Serbia
}

\begin{abstract}
Among its many roles, typography also serves to make a text more legible and readable, allowing the reader to follow the content flow with more ease. Typographic hierarchy, in turn, with its use of different logical and visual tools, serves to establish an order of importance of different text elements. To emphasize certain elements - i.e. create eye-catchers, typographers usually resort to making bigger and bolder items. In this paper we wish to examine whether white space can also serve as a means of emphasis. While several studies have already proven that white space influences consumer perception in advertising, no one has yet investigated the effects of white space on text scanning. With that in mind, we examined whether white space could contribute to the effectiveness and speed of text scanning. We used eye-tracking technology to collect accurate quantitative and visual data. Although the results did not show that white space has a positive effect on scanning speed or text structure memorability, we have noted a difference in the eye-movement pattern, which raises hope and leads us to believe that further research is needed.
\end{abstract}

Key words: typography, typographic hierarchy, white space, text scanning, eye-tracking

\section{INTRODUCTION}

Typography is a refined craft that makes language visible (Cullen, 2012). It uses type to communicate (Black et al, 1992) and interpret a message (Bringhurst, 2018). Typographers cannot force anyone to read, but they can make a document clear, accessible, and adaptable (Black et al, 1992). Except it should attract attention, reveal content and meaning of a text, connect the text with other elements and provide reading comfort, typography should also explain structure and framework of a text, i.e. enables navigation through the content flow (Black et al, 1992; Lupton, 2010; Bringhurst, 2018).

Although the purpose of typography is mostly defined as the readability improvement, "one of design's most humane functions is, in actuality, to help readers avoid reading (Lupton, 2010)." Apart from novels, readers rarely read documents from beginning to end (Black et al, 1992). Before processing on a wordlevel, a reader is scanning a text by identifying its physical appearance: format, size and complexity; reader recognises different degrees of information on a global level, by finding and collecting structural signs and characteristics (Black et al, 1992), which helps him/her in processing content quickly to extract elements for immediate use (Lupton, 2010). The documents must be adapted to this purpose of the text (Black et al, 1992), and this is where the hierarchy comes into play.

Typographic hierarchy makes the content easy to scan, helps the composition to be unambiguous, clean, clear and understandable (Ambrose and Harris, 2006; Lupton, 2010; Samara, 2014). "Hierarchy is a logical and visual way to express the relative importance of different text elements by providing a visual guide to their organisation (Ambrose and Harris, 2006)." Content should be organised logically rather than stylistically (Lupton, 2010), because so-designed messages are not just more comfortable and quicker read, but remain remembered (Müller-Brockmann, 1996). "Designers conduct hierarchy with typographic, spatial, and graphic factors (Cullen, 2012)." The human eye experiences bigger and bolder items as more important than smaller and lighter ones. Still, typographic distinction alone is sometimes insufficient to discern hierarchy levels but is achieved using the space (Black et al, 1992). When it comes to the use of space, there are two opposing opinions.

One advocates that both black and white space are equally important because disposition and amount of area which surrounds text also convey information. The other opinion is coming from the fierce proponents of visual density. They claim that one page full of well-organised information is better than multiple ones with plenty of white space (Lupton, 2010).

Research in the field of typography mostly focuses on the printed elements of a page, leaving white space both literally and metaphorically on the margins. Where the influence of white space on the perception of the advertised product has been proven in several studies (Pracejus et al, 2006; Jacobs and Poillon, 2012; Olsen et al, 2012; Loh, 2013; Kwan et al, 2017), its effect on text scanning has not been examined. 
This paper aims to fill that gap, investigating whether white space has an impact on the speed and effectiveness of text scanning.

\section{METHODS}

The goal of this study is to see if white space contributes to text scanning speed and effectiveness, i.e. can white space be applied as an eye-catcher. Additionally, we will check whether white space will impact answer accuracy, text's structure awareness and memorability. Therefore we formulated the hypotheses. $\mathrm{H}_{0}$ : White space does not have a significant impact on text scanning speed and effectiveness.

$\mathrm{H} 1$ : White space does have a significant impact on text scanning speed.

$\mathrm{H} 2$ : White space does have a significant impact on text scanning effectivity.

H3: White space does have a significant impact on the text's structure awareness.

H4: White space does have a significant impact on the memorability.

For this purpose, two layouts were designed: control and experimental one. We chose two different texts ( $A$ and $B$ ) with the same number of words and an approximately equal number of characters. The two texts were prepared as both control and experimental stimuli, which form four different stimuli. According to the experimental 2x2 design (Novaković et al, 2013) participants were assigned to one of the following four groups: Group 1: reads the text Ac, then Be; Group 2: reads the text Ae, then Bc; Group 3: reads the text $B c$, then $A e$; Group 4: reads the text $B e$, then $A c$.

\subsection{Tools}

We used Lenovo Z51 laptop PC, Eizo Color Edge CG241W LCD monitor, Gazepoint GP3 eye-tracking device, Gazepoint Analysis 3.5.0 and Gazepoint Control 3.5.0 software. According to Gazepoint official recommendation, the experimental room was shaded, excluding both direct and indirect light sources. During the experiment, PC was connected to the monitor (which projected stimuli) and to the eyetracking device, which was set under the monitor. Gazepoint GP3 eye-tracking device contains a $60 \mathrm{~Hz}$ frequency camera, which is limited in reading text tasks, but it is sufficient for visual search ones.

\subsection{Participants}

Twenty-nine students and assistants from the Faculty of Technical Sciences, University of Novi Sad began the experiment session. Due to the impossibility of calibration or data analysis, data on 20 respondents was collected. The selection of respondents was random, and participation in the experiment on a voluntary basis. Respondents were randomly assigned to one of four groups.

\subsection{Design of stimuli}

This experiment manipulates white space, while other text parameters remain constant. Both stimuli have two hierarchy levels, where the first one (subtitles) is set in bold, and the second one in a regular cut. The stimulus control (c) follows an essay layout, containing familiar white space. Experimental stimulus (e) is set in two columns, where the first hierarchy level is surrounded by a greater amount of white space. Other parameters of the stimuli layout were designed in accordance with the researched literature. Therefore, the type was set in Arial Regular, because of its familiarity and wide-spread use. A gradation of $11 \mathrm{pt}$ was selected, with a spacing of $13.2 \mathrm{pt}$. All stimuli were arranged without hyphenation. Line density was between 75 and 90 characters per line. Figures 1 and 2 show the layout of the control and experimental stimuli, respectively.

For textual content of the stimuli, popular science articles were selected, which were filled with a lot of information that is not generally known, nor does it fall under the engineering profession. The two articles "Why do we drink cow's milk?" and "Invasion of Bamboo" were taken from the platform naukakrozprice.rs. To achieve the same number of characters and an approximate number of words in both texts (3681 characters; 616 words in text A and 607 words in text B), some of the sentences are reformulated or moved, without changing the content and context. The subheadings were arbitrarily chosen so that they refer to the paragraph and guide participant clearly in answer search. In order to make a difference in the number of sections, text $A$ is adjusted to four, and for text $B$ to five paragraphs. Texts $A$ and $B$ are entirely independent and can be read in any order. By combining two texts and two formatting modes, four stimuli were prepared: (1) Control $A(A c)$, (2) Control B (BC), (3) Experimental $A$ (Ae) and (4) Experimental B (Be). 


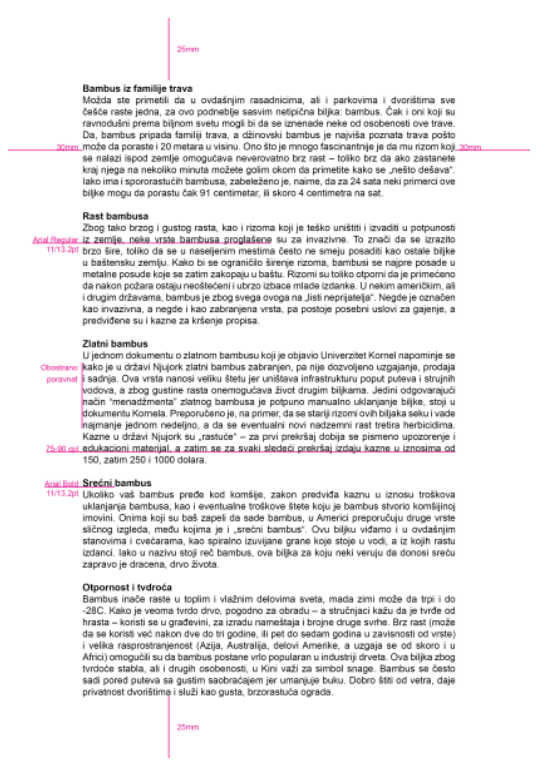

Figure 1: Stimuli control layout

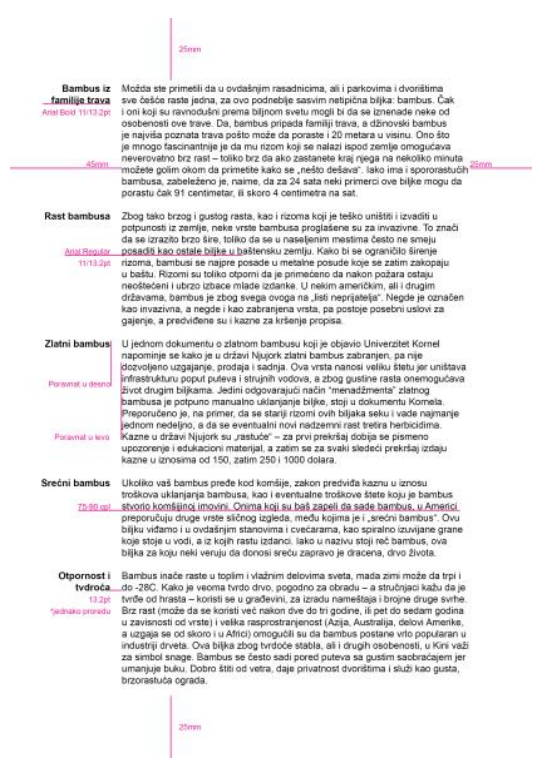

Figure 2: Experimental stimuli layout

In addition to these primary stimuli, two more were prepared, with questions for text $A$ and $B$. The stimuli with questions were also set in 11 pt Arial, centrally aligned, in the middle of the observed surface. The questions are formulated so that they have a term that corresponds to one of the subheadings so that the respondents first find it, and then continue reading the matching paragraph, find the required information and give the answer. The question for text A was: "When did the mutation of milk intolerance occur?"; for text B: "In which country is golden bamboo banned?" In the former they were supposed to find the subtitle "Mutation of intolerance", and then in the paragraph "about 7500 years ago", and in the later, subtitle "Golden Bamboo", followed by "in the state of New York."

Gazepoint Analysis 3.5.0 offers video, web page, screen, text file in .txt format, and image analyse option but does not provide one for a .pdf extension file. Therefore, the stimuli were prepared as images in .png format.

\subsection{Procedure}

To avoid individual differences between the participants, each of them had to encounter both texts and both ways of stimuli design. Additionally, to collect the observed variables for each participant in both control and experimental conditions, avoiding the influence of both the order of the texts and the order of the design, four groups were formed, into which the participants were randomly assigned: Group 1 reads text $A c$, then $B e$; Group 2 reads text $A e$, then $B c$, Group 3 reads text $B c$, then $A e$, group 4 reads text Be, then Ac.

At the beginning of each experimental session, every participant was informed about the experimental procedure. A 9-point calibration followed the explanation, afterwards data collection of eye movements began. After the experiment sessions with all subjects were completed, AOls (areas of interest) for each subheading and the part of the paragraph that contains the answer were defined.

\section{RESULTS}

Before performing a statistical test, we checked whether the continuous variables, which are the focus of the research, were normally distributed. Since the sample is smaller than 50 , we used the Shapiro-Wilk normality test. 
Table 1: Results of examing variables normal distribution

\begin{tabular}{|l|l|l|l|l|l|l|}
\hline & $\begin{array}{l}\text { Answer time } \\
{[\mathrm{sec}]}\end{array}$ & $\begin{array}{l}\text { AOI answer } \\
\text { time to 1st } \\
\text { view [sec] }\end{array}$ & $\begin{array}{l}\text { AOI answer } \\
\text { time viewed } \\
{[\mathrm{sec}]}\end{array}$ & $\begin{array}{l}\text { AOl answer } \\
\text { time viewed } \\
{[\%]}\end{array}$ & $\begin{array}{l}\text { AOl number of } \\
\text { fixations }\end{array}$ & $\begin{array}{l}\text { AOI answer } \\
\text { revisits }\end{array}$ \\
\hline $\mathrm{A}$ & $\mathrm{p}_{\mathrm{c}}<0.01$, & $\begin{array}{l}\mathrm{p}_{\mathrm{c}}<0.01, \\
\mathrm{p}_{\mathrm{e}}<0.01\end{array}$ & $\begin{array}{l}\mathrm{p}_{\mathrm{c}}>0.05, \\
\mathrm{p}_{\mathrm{e}}<0.05\end{array}$ & $\begin{array}{l}\mathrm{p}_{\mathrm{c}}>0.05, \\
\mathrm{p}_{\mathrm{e}}<0.05\end{array}$ & $\begin{array}{l}\mathrm{p}_{\mathrm{c}}>0.05, \\
\mathrm{p}_{\mathrm{e}}>0.05\end{array}$ & $\begin{array}{l}\mathrm{pc}>0.05, \\
\text { pe }>0.05\end{array}$ \\
\hline $\mathrm{p}<0.01$ & $\mathrm{p}_{\mathrm{c}}>0.05$, & $\begin{array}{l}\mathrm{p}_{\mathrm{c}}<0.01, \\
\mathrm{p}_{\mathrm{e}}<0.01\end{array}$ & $\begin{array}{l}\mathrm{p}_{\mathrm{c}}>0.05, \\
\mathrm{p}_{\mathrm{e}}<0.01\end{array}$ & $\begin{array}{l}\mathrm{p}_{\mathrm{c}}>0.05, \\
\mathrm{p}_{\mathrm{e}}<0.01\end{array}$ & $\begin{array}{l}\mathrm{p}_{\mathrm{c}}>0.05, \\
\mathrm{p}_{\mathrm{e}}<0.01\end{array}$ & $\begin{array}{l}\mathrm{pc}=0.05, \\
\mathrm{pe}<0.05\end{array}$ \\
\hline
\end{tabular}

As Table 1 shows, the observed variables are generally not normally distributed. Therefore we used a nonparametric test of independent groups to compare continuous variables between groups, i.e. ManWhitney U test.

Table 2: Results of the Man-Whitney $U$ test for continuous variables, text $A$

\begin{tabular}{|l|l|l|l|l|}
\hline & $\begin{array}{l}\text { Mann- } \\
\text { Whitney U }\end{array}$ & Z & $\begin{array}{l}\text { Asymp. Sig. } \\
\text { (2-tailed) }\end{array}$ & r \\
\hline Answer time & 33.000 & -1.285 & 0.199 & \\
\hline Answer AOI_timetofirstview & 37.000 & -0.983 & 0.326 & \\
\hline Answer AOI_timeviewed* & 18.000 & -2.419 & 0.016 & 0.5409 \\
\hline Answer AOI_timeviewedpercent* & 18.000 & -2.419 & 0.016 & 0.5409 \\
\hline Answer AOI_fixations & 29.500 & -1.563 & 0.118 & \\
\hline Answer AOI_answerrevisits & 42.000 & -0.609 & 0.542 & \\
\hline Subtitle AOI_timetofirstview & 42.000 & -0.605 & 0.545 & \\
\hline Subtitle AOI_timeviewed & 26.000 & -1.814 & 0.070 & \\
\hline Subtitle AOI_timeviewedpercent & 26.000 & -1.814 & 0.070 & \\
\hline Subtitle AOI_fixations* & 15.500 & -2.666 & 0.008 & 0.59607 \\
\hline Subtitle AOI_revisits* & 22.500 & -2.143 & 0.032 & 0.47929 \\
\hline
\end{tabular}

The results of the Mann-Whitney $U$ test show differences between the groups. In Table 2 we note that statistically significant differences are present in the absolute and relative time viewed of the Answer AOI, as well as in the number of fixations and the number of revisits to the Subtitle AOI. In all differences between the groups, Cohen's criteria are large $(r \sim 0.5)$. For all the mentioned differences, the lower median values refer to the experimental group.

Table 3: Results of the Man-Whitney $U$ test for continuous variables, text $B$

\begin{tabular}{|l|l|l|l|l|}
\hline & $\begin{array}{l}\text { Mann- } \\
\text { Whitney U }\end{array}$ & $Z$ & $\begin{array}{l}\text { Asymp. Sig. } \\
\text { (2-tailed) }\end{array}$ & r \\
\hline Answer time & 39.500 & -0.794 & 0.427 & \\
\hline Answer AOI_timetofirstview & 44.000 & -0.460 & 0.646 & \\
\hline Answer AOI_timeviewed & 42.000 & -0.605 & 0.545 & \\
\hline Answer AOI_timeviewedpercent & 42.000 & -0.605 & 0.545 & \\
\hline Answer AOI_fixations & 37.000 & -0.985 & 0.325 & \\
\hline Answer AOI_answerrevisits & 46.000 & -0.304 & 0.761 & \\
\hline Subtitle AOI_timetofirstview & 39.500 & -0.794 & 0.427 & \\
\hline Subtitle AOI_timeviewed* & 24.500 & -1.928 & 0.054 & 0.43119 \\
\hline $\begin{array}{l}\text { Subtitle AOI } \\
\text { timeviewedpercent* }\end{array}$ & 24.500 & -1.928 & 0.054 & 0.43119 \\
\hline Subtitle AOI_fixations* & 13.000 & -2.857 & 0.004 & 0.63876 \\
\hline Subtitle AOI_revisits* & 15.000 & -2.713 & 0.007 & 0.60662 \\
\hline
\end{tabular}


In Table 3, we notice that statistically significant differences are present in the absolute and relative time viewed, as well as in the number of fixations and the number of revisits to the Subtitle AOI. In all differences between the groups, Cohen's criteria shows medium to large $(0.3<r<0.5)$ and large $(r>0.5)$ value. For all the above differences, the experimental group of stimuli has a lower median value.

The Chi-square test was used to test the differences between groups for categorical variables. Since all participants gave the correct answer for both text A and text B, without a statistical test, we conclude that there is no difference between the control and experimental group. Neither subtitles number accuracy, nor subtitles memory accuracy show differences between the groups, which we see in Table 4.

Table 4: Results of the Chi-square test

\begin{tabular}{|l|l|l|}
\hline & Text A & Text B \\
\hline Subtitles number accuracy & $\chi^{2}=0, p=1.000$ & $\chi^{2}=0.833, p=0.361$ \\
\hline Subtitles memory accuracy & $\chi^{2}=2.343, p=0.673$ & $\chi^{2}=0.933, p=0.817$ \\
\hline
\end{tabular}

\section{DISCUSSION}

The first issue we encountered in data analysis is the inefficient sample size for the two-factor ANOVA test. Therefore we used a more robust, nonparametric, Man-Whitney $U$ test. In categorical variables (answer accuracy, subtitles number accuracy and subtitles memory accuracy) differences between groups were not statistically significant. The primary observed continuous variable (answer time) hasn't shown a statistically significant difference between control and experimental groups. However, some other variables did. The number of fixations and of revisits to the subtitle AOI is significantly smaller in the experimental group in both texts. According to all the above, the formulated hypothesis $\mathrm{H}_{0}$ (The use of whiteness does not have a significant influence on speed and effectivity of visual search of the text) cannot be rejected.

\subsection{Heat Map analysis}

The Heat Map visualises the length of the fixations with a range of colours from light blue, through dark, orange and red, where light blue corresponds to the shortest fixation and red to the longest. If there is no colour, it means that there was no fixation in that part of the screen at a particular moment. The following figures (3-10) show the heat maps for every group, in five representative moments.
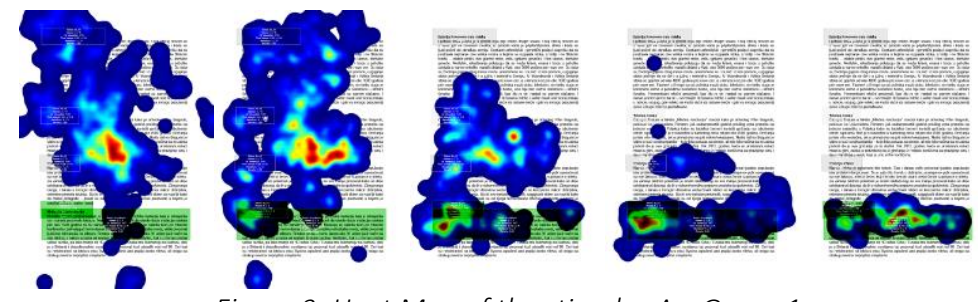

Figure 3: Heat Map of the stimulus Ac, Group 1
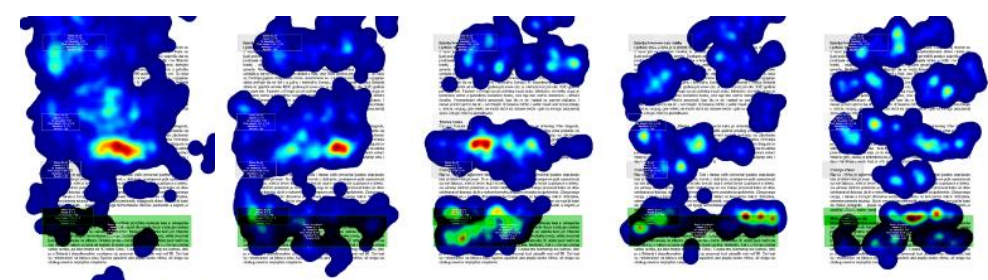

Figure 4: Heat Map of the stimulus Ac, Group 4 

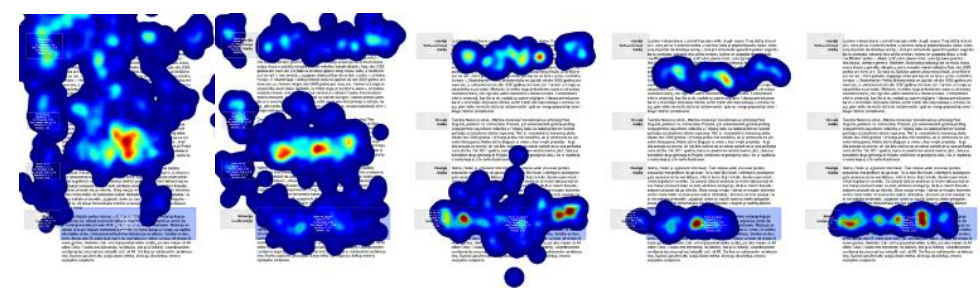

Figure 5: Heat Map of the stimulus Ae, Group 2
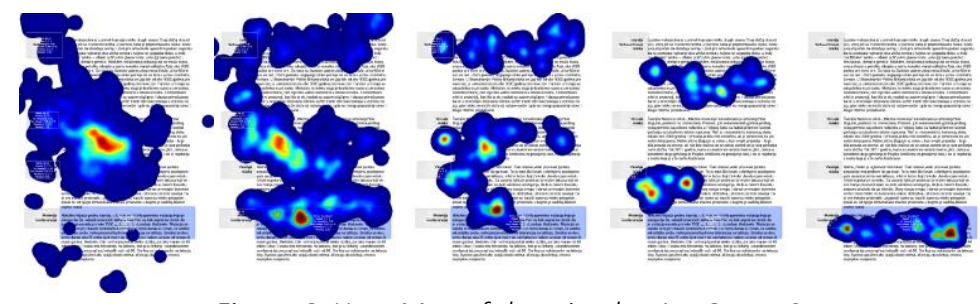

Figure 6: Heat Map of the stimulus Ae, Group 3
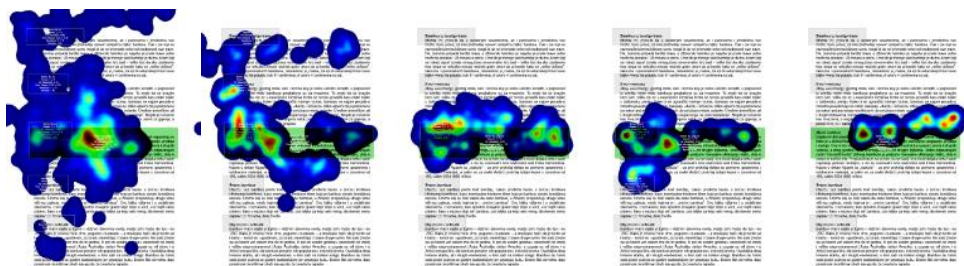

Figure 7: Heat Map of the stimulus Bc, Group 3
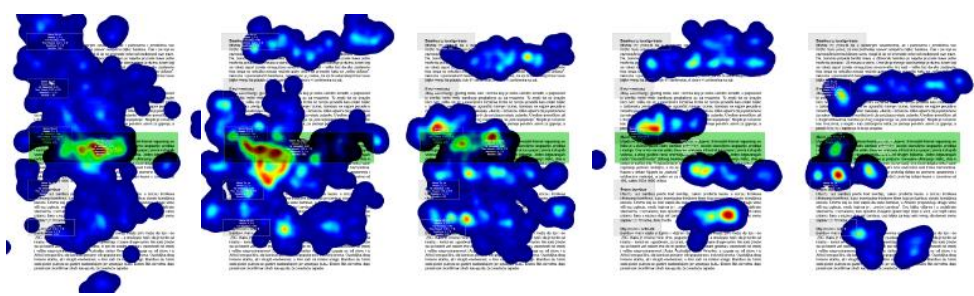

Figure 8: Heat Map of the stimulus Bc, Group 2
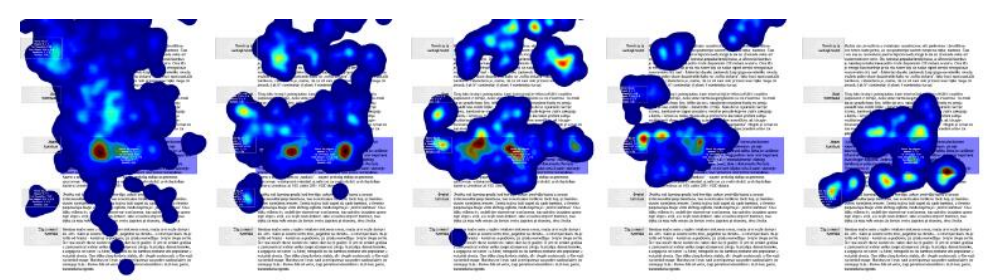

Figure 9: Heat Map of the stimulus Be, Group 4

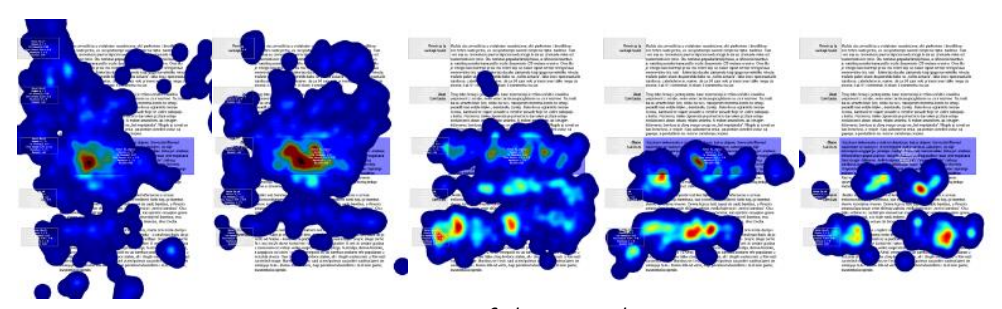

Figure 10: Heat Map of the stimulus Be, Group 1

At the beginning of each collective observation, we notice established movements from the upper-left edge of the page to the field of interest. We also notice that on the experimental stimulus, observed in relative time, the gaze is directed faster towards the field of interest, while on the control stimulus, it is more distracted. At certain moments, we also notice completely separate concentrations of fixations 
(some respondents searched for the region of interest longer than others), which confirms the scattering of the distribution of the time of finding the answer.

\section{CONCLUSIONS}

The typographic hierarchy inevitably has a role in page navigation, i.e. more efficient text scanning. Among the many ways to achieve typographic hierarchy, the influence of white space is not extensive in empirical research. However, design practice claims that white space contributes to a certain extent to the perception of the visual hierarchy. This claim has been experimentally tested, by designing control and experimental stimuli, with the usual and unconventional use of white space, respectively. The eyetracking method has proven to be very useful in the visual search experiment, as it offers plenty of quantitative and visual data, providing a very detailed analysis of the human eye movements. In the quantitative data analysis, the biggest obstacle was the small sample size, as well as the non-normal distribution of variables. Therefore nonparametric tests were used, which are more robust than parametric ones.

The results of the experiment did not show that white space impacts answer time, answer correctness, nor text structure memory. Therefore the null hypothesis was not rejected. However, results noted a significantly less number of fixations and $\mathrm{AOI}$ revisits for the experimental stimuli. From both quantitative and visual data, we notice that there is no difference in the first subtitle AOI. This phenomenon can be explained by the habit of Western civilizations to start reading or scanning the text from the upper left page area. This notice also shows that eye-catchers that use white space are not strong enough, because they do not draw attention to themselves first, but allow the eye to start moving through the text by inertia. However, the results showed that other subheadings surrounded by white space generally require fewer fixations and fewer eye revisits. This observation provides a basis for additional, more thoroughly prepared experiments to prove that white space contributes to more efficient text scanning and memory.

\section{ACKNOWLEDGMENTS}

This research (paper) has been supported by the Ministry of Education, Science and Technological Development through the project no. 451-03-68/2020-14/200156: "Innovative scientific and artistic research from the FTS (activity) domain".

\section{REFERENCES}

[1] Ambrose, G., Harris, P.: "The Fundamentals of Typography", (AVA Publishing, Lausanne SA, 2006.).

[2] Black, A., Stiff, P., Waller, R.: "Designing Business Documents", (Redhill: Monotype Typography Ltd, 1992.).

[3] Bringhurst, R.: "Elementi tipografskog stila", (Hrvatsko dizajnersko društvo, Zagreb, 2018.).

[4] Cullen, K.: "Design elements typography fundamentals: a graphic style manual for understanding how typography affects design", (Rockport MA, Beverly, 2012.).

[5] Jacobs, L., Poillon, C.L.: "White Space in Newspaper Grocery Advertising: Some New Findings", Journal of Current Issues \& Research in Advertising 14, 69-75, 2012. doi: 10.1080/10641734.1992.10504990.

[6] Kwan, C.M.C., Dai, X., Wyer, R.S.: "Contextual Influences on Message Persuasion: The Effect of Empty Space", Journal of Consumer Research 44, 448-464, 2017. doi: 0.1093/jcr/ucx051.

[7] Loh, S.L.: "Effects of White Space on Consumer Perceptions", MSc thesis, University of San José, 2013.

[8] Lupton, E.: "Thinking with type: a critical guide for designers, writers, editors, \& students", (Princeton Architectural Press, New York, 2010.).

[9] Müller-Brockmann, J.: "Grid systems. ", (Niggli Verlag, 1996.).

[10] Novaković, D., Milić, N., Milosavljević, B.: "Animated vs. Illustrated Software Tutorials: Screencasts for acquisition and Screenshots for Recalling", International Journal of Engineering Education, 29, 1013-1023, 2013.

[11] Olsen, G.D., Pracejus, J.W., O'Guinn, T.C.: "Print advertising: White space", Journal of Business Research 65, 855-860, 2012. doi: 10.1016/j.jbusres.2011.01.007. 
[12] Pracejus, J., Olsen, D., O'Guinn, T.: "How Nothing Became Something: White", Journal of Consumer Research 33, 82-90, 2006. doi: 10.1086/504138.

[13] Samara, T.: "Design Elements: Understanding the Rules and Knowing When to Break Them", (Second ed. Gloucester: Rockport Publishers, 2014.).

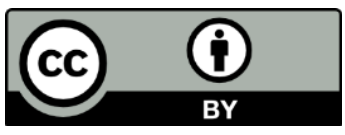

(C) 2020 Authors. Published by the University of Novi Sad, Faculty of Technical Sciences, Department of Graphic Engineering and Design. This article is an open access article distributed under the terms and conditions of the Creative Commons Attribution license 3.0 Serbia

(http://creativecommons.org/licenses/by/3.0/rs/). 